it ran a favourable course, and he was discharged to rejoin his corps on Oet. 10th.

The principal diseases occurring among the native followers were ague, dysentery, ophthalmia, ulcers, and venereal disorders, and they suffered from these affections much more severely than the fighting men. Many of the followers appeared to be weak and sickly men, who should not have been allowed to accompany the expedition at all, and most of them seemed to have contracted a slight scorbutic taint from the combined effects of hard work and insufficient and monotonous diet. Lime-juice of course was freely used in these cases, but fresh meat seemed to be of greater value, not only as nourishment but as an antiscorbutic. Some of the cases of dysentery among the followers proved very intractable and resisted all treatment; nearly all of them were saved by careful nursing and plenty of nourishment, but one proved fatal. This was the only fatal case that occurred in the General Hospital from August 25th to October 13th, the period during which I was in charge. The solution of nitrate of silver (ten grains to one ounce) proved effectual in most cases of ophthalmia when taken in time, but in one unfortunate instance vision had been destroyed before the patient applied for treatment. Most of these cases seem to have occurred through the agency of dirt and flies, the men generally neglecting to wash their eyes and to prevent flies from settling upon them. Two cases of Guinea-worm occurred, but they presented no features of interest. I watched for cases of hæmaturia from the presence of the bilharzia, but met with none.

In conclusion, I may mention that Rear-Admiral Sir William Hewett, K.C.B., V.C., commanding at Suez, frequently visited the General Hospital in the Hydaspes, and approved of all the arrangements.

Monghyr, Bengal.

\section{LIVER ABSCESS PRECEDED BY ACUTE, AND ACCOMPANIED BY CHRONIC, DYSEN-} TERY ; CURE.

\section{By J. H. BRANNIGAN, L.R.C.P., L.R.C.S. EDIN.}

THE following is a short report of a case that came under my notice in April of last year, which from the serious nature of the complaint and the simplicity in the method of its treatment I think worthy of record.

Early in the month above mentioned I was summoned by the American mission to see a certain Giorgis, native of Luxor, on the Nile, Upper Egypt. He was en route for Cairo accompanied by his aged father, there to seek advice and treatment at the hands of some European surgeon. Hearing from the Rev. Dr. Hogg, chief of the American mission in Egypt, that there was an English surgeon at hand the father and patient begged that I might at once be called in.

Appearance of patient on visit. - The patient, aged eighteen, was tall and greatly emaciated, wore an extremely anxious expression, face mottled, conjunctivæ slightly if at all jaundiced, voice feeble-iin short, much debilitated.

History of case.--Six months ago he had an attack of dysentery; this finally became chronic. In the early part of January, 1882, the patient began to complain of pain in the region of the liver, associated with fever, sometimes absent, but always returning, especially in the evening, accompanied by perspiration. He sought advice, and was frequently blistered over the seat of pain. Later on, inability to retain food, which was shortly vomited after taking it. Difficulty in breathing was also noticed; breathing was laboured, "thick" as he called it. Prostration went on, and stools to the number of three or four per diem were passed. The temperature was now taken $\left(102^{\circ} \mathrm{F}\right.$.) pulse 90 . On inspection the abdominal region showed distinct swelling at the epigastrium, and slightly to the left of the middle line. Palpation could not detect fluctuation, but made out an annular hardness on the surface of the tumour, with a depressed centre, easily felt through the abdominal walls.

Diagnosis.-Taking into consideration the history of the case-viz, attack of dysentery some months previously, and now in existence as chronic; presence of a tumour; remittent nature of the fever,- I concluded it was one of liver abscess situated in the left lobe.
Explorctory examination. -A five explorntory trocar and canaula (made by Collin et Cie., Tiue de l'Lccie de Médecine, Paris) was inserted at the most prominent seat of the tumour, where I was of opinion adhesions had set up with the abdominal parietes. On withdrawal of the trocar I waited anxiously a few minutes, and was pleased to see a thick creamy chocolate-coloured pus appear.

The patient and his father seeing woy statements verified by the exploratory examination, no longer mistrusted, but implored me to open the abscess at once. I promised to do so next morning. The question was $(a)$ aspiration, or $(b)$ free incision. The first was not possible, as there was no aspirator. The second, free incision at the seat, where I was confident adhesions had formed, seemed to specially commend itself, aided by the Lister spray. Having no spray apparatus, I adopted a method that would minimise the danger of septicæmia-i.e., insertion of a moderately large-sized trocar and cannula. The night preceding the operation the patient was very feeble after walking to my house from the American mission; felt sick, and complained of the old pain in the hypogastrium. Temperature $104^{\circ} \mathrm{F}$.; face flushed, and large beads of perspiration over the forehead. I gave the patient some milk, beaten up with an egg and an ounce of whisky. Sent him to bed in my own house, his future hospital. 8 A.M. : The patient passed a restless night; temperature $102^{\circ} \mathrm{F}$. The dressings having been prepared-viz., cotton-wool, saturated in $\mathbf{I}$ in 20 carbolic acid lotion, and some folds of Lister's antiseptic gauze, with oiled silk, - I carefully sponged the abdominal surface with 1 in 20 carbolic lotion, selected the point of annular hardness, raised up the skin, and made an incision, in order to render penetration of trocar and cannula painless. I then took out of a solution of $I$ in 20 carbolic acid lotion the trocar and cannula, drove them well into the tumour, and withdrew the trocar. Immediately more than two pints of healthy pus, mixed with liver débris, came away. No more pus coming, the parts were carefully sponged with 1 in 20 solution of carbolic acid, tied in cannula, and placed a piece of oiled silk round it at the orifice of the wound, to obviate any absorption of pus; carbolised cotton-wool was placed round to prevent any filtering of pus at the edges of the dressing; over the whole the Lister gauze was placed, and kept in situ by a large towel passed round the body and fixed at the side by three safety pins. The patient expressed himself much relieved, and shortly after took some milk beaten up with egg and whisky. 8 P.M.: Dressing removed; a few ounces of pus had oozed out of cannula. I applied a fresh dressing after cleaning the parts carefully in 1 in 20 carbolic acid lotion. Temperature $103^{\circ} \mathrm{F}$; sweating on forehead slight; no pain, no sickness ; had had milk and some chicken broth. The usual dressing was continued twice daily, the pus still continuing healthy. The cannula remained in tweive days without causing any irritation save a slight blush at the point of insertion. Attention was paid to the diet, and stimulants in the shape of claret were given. The discharge had now almost ceased; the swelling disappeared, and one morning the cannula was found two-thirds out and no discharge visible. I removed the cannula, replacing it by a drainage-tube previously dipped in 1 in 20 carbolic acid solution. Examination of the cannula showed the part that was in the abscess to be discoloured by the bile acids. Temperature never varied from $99^{\circ}$ A. M. to $101^{\circ}$ P.M.; pulse 75 to 80 . The appetite was good, and food in the shape of milk, eggs, and chicken broth was partaken of with relish. The breathing became free, and the sickness ceased from the day the abscess had been evacuated. Third week: The dressing tube was now difficult to introduce, and no discharge visible; still I could detect a slight return of swelling, there was a rise of fever, and an outbreak of perspiration over the forehead. I reintroduced the trocar and cannula, previously dipped in a 1 in 20 carbolic lotion, withdrew the trocar, and about three onnces of pus, mixed with liver débris, came away. This was the last discharge in any quantity. The case went on rapidly well, and in twenty-three days the patient left cured, restored in flesh and strength-a different person to what he was when first seen.

About this time $I$ saw in THE LANCET some reports on the use of nitrate of silver in enema in a case of chronic dysentery. At the end of the second week I gave an enema of twenty grains of nitrate of silver to three pints of tepid water, without any effect. Then an enema later on of forty grains to three pints of water. Stools were less. Finally I gave sixty grains of nitrate of silver to three pints 
$0:$ water, and although the fluid was retained about four inimutes it caused no pain. After this stools, three, two, and oue, of more solid consistence, were passed, and before the patient left he had not more than one stool daily, and that healthy in appearance. All through the pus was free from smell and quite healthy.

\section{CASE OF DIABETES ; DEATH THIRTY HOURS AFTER FIRST VISIT.}

By ED. GEO. WHITTLE, M.D. LoND., \&c.

SHARING in the general sympathy which the harsh censure of Dr. Blades has evoked from the profession, I am induced to send you the following report.

On Monday, June 25th, I was called to see a man whom I found lying helpless in bed, with his feet hanging over the side and uncovered, as though he had failed in an attempt to get back. He looked about thirty-five years of age, muscular, spare, but not emaciated; his hands and feet were cold and 6 anosed; his breathing was laborious, rapid, and deep; he conld answer questions, but so slowly and with such evident - ffort, that I put no more than were needed to ascertain that he had his mental faculties. The pupils were equal; there was no paralysis, but when the eyelid was raised, it fell back sluggishly. Chest walls were highly resonant, and the respiration was everywhere loud, harsh, and bronchial, expiration being almost as loud and long as inspiration. Heart healthy. Mucous membrane of lips and eyelids red. Tongue dry and brown. Throat dusky red, with vesicular eruption on soft palate. Palse 140 ; temperature $97.8^{\circ}$. Urine (none saved) reported to be healthy in appearance micturition normal. There was neither odema nor anæmia. The case was clearly one of diabetic dyspnoa, running rapidly to a fatal issue. He soon became unconscious, passed his urine in bed, and died on the evening of the next day. I certified without having examined the urine.

The following is the history as obtained from his wife. Had always been healthy and temperate. A year ago he was treated for an attack of diarrhcea, but had had no medical advice since, nor had he missed a day's work (shoeinaking). On June 19th, a week before death, he had sore-thr.at. On the 21 st his wife wished to send for a doctor, but he said there was no need, as his throat was getting better. For some few weeks he had occasionally complained of fatigue, which he attributed to the hot weather. His sight was slightly impaired. This, he thought was due to sitting too closely at work. He worked as usual on the 23rd (Saturday), but in the evening felt tired and drowsy. The next morning he felt as well as usual, but his wife induced him to remain in bed for the sake of rest. He had no symptoms causing anxiety to himself, and it was only on account of his throat that his wife wished him to have medical advice. On the 25 th he arose at 6 A.M., and his wife ohserved that his breathing was short while dressing. About 1.30 P. M. I saw him in the condition above described.

Remarks. - Having the advantage of the knowledge derived from a study of Dr. Blades' case and a paper read by my friend, Dr. E. Mackey, in which the diagnosis between hysteric, uræmic, and diabetic dyspnoea was ably pointed out, I was saved all trouble in diagnosis. To remove all doubt, however, I drew off some mine after death. It contained albumen and sugar in abundance. I am not ashamed to confess that had this man consulted me on the Friday evening before his death he might possibly have left me with his glycosuria undetected. Very few men in general practice examine the urine at a first consultation as a matter of routine; but unless this rule be observed, anyone may overlook an obscure renal affection, acsepting the suggestion of the patient that his malasie is due to overwork, confinement, heat of the weather, \&c. Are we to be held almost criminally responsible in such cases when the inevitable and natural sequence occurs without its having been prematurely announced? Are we who have the most complex and inconstant phenomena of disease to interpret never to be forgiven an oversight? We cannot avoid them. He who asserts that he cannot err must have had but little experience in the practice of medicine, and I should be sorry to trust myself to his infallibility. Are not most cases of glycosuria, as of albuminuria, already chronic when they first come under notice? Is it not often impossible to assert when

they began? The above case will be classed by many as "acute diabetes"; but if I assert that the man may have had glycosuria for many years, who is to prove the contrary? Brighton.

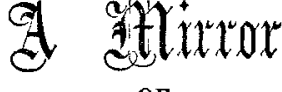

\section{HOSPITAL PRACTICE, BRITISH AND FOREIGN.}

Nu.la autem est alia pro certo noscendi via, nisi quamplurimas et morborum et dissectionum historias, tum aliorum tum proprias collectas habere, et inter se comparare.-MoвqAGNI De Sed, et Caus. Morb., lib. iv. Procmium.

\section{CITY OF LONDON HOSPITAL FOR DISEASES} OF THE CHEST.

MOVABLE TUMOUR IN THE ABDOMEN, SIMULATING MOVABLE KIDNEY; NECROPSY; DISPLACEMENT OF LIVER.

(Under the care of Dr, EUSTACE SMrTH.)

For the notes of the following case, which is of considerable interest from a diagnostic point of view, we are indebted to Mr. T. H. Waller, M.R.C.S., L. R.C.P. Lond., resident medical officer.

J. $\mathrm{S}-$-, aged thirty-four, married, was admitted on June 4th, suffering from advanced phthisis and laryngitis. While in hospital she drew attention to a lump in the right side of her abdomen, which she had noticed for the first time after her last confinement three years previously. It caused her no inconvenience whatever-no pain except on pressure, and then very slight. She had noticed that it often shifted about from one place to another.

On examination, a tumour was felt in the right side of the abdomen, below the margin of the ribs, with the following characters: It was solid, firm, oval in shape, with the long axis parallel with that of the body, and easily movable. When the patient lay on her back, the tumour could be grasped between the thumb and fingers in the right loin, but when she turned on her left side the tumour could be felt in the middle line of the abdomen, returning to its original place immediately the patient lay on her back again. The right kidney could not be felt positively in its natural situation. There was no dulness below the edge of the ribs in the natural position, but when the tumour was pushed forward to the anterior surface of the abdomen, it was found to be dull. The urine was examined several times, and always free from albumen, but contained latterly an abundant deposit of urates. There was no history of any urinary trouble. The tumour was thought undoubtedly to be a "movable kidney." The patient died on July 25 th.

Necropsy. - The right lobe of the liver extended three inches and a half below the level of the ribs, reaching downwards just below the highest point of the erest of the ilium; from its emergence from under the ribs downwards, it nowhere measured more than an inch in thickness. Following the same mode of examination, the movement of this part of the liver corresponded in every way with what had been felt during life : when grasped between the thumb and fingers this part of the liver was folded upon itself, thus giving the tumour the oval shape, and the resemblance to that of the kidney. When removed the liver weighed $48 \mathrm{oz}$, and was healthy. The gall-bladder contained three gallstones, the size of ordinary marbles, with several wellmarked smooth facets on each. The gall-bladder was full, but not distended ; the duct leading from it was occluded, not admitting the largest end of a post-mortem needle further than its entrance. The right kidney was in its natural situation, and healthy.

\section{LEICESTER INFIRMARY.}

NOTES ON A CASE OF HYDROPHOBIA PRESENTING SOME PECULIAR SYMPTOMS ; NECROPSY ; REMARKS.

(Under the care of Dr. CoOpER.)

FOR the following notes we are indebted to $\mathrm{Mr}$. C. J. Bond, F.R.C.S., house-surgeon.

A healthy agricultural labourer, aged fifty-six, was bitten by a large retiliever dog, on Jan. 20th, 1853, on the left 